\title{
ÉTICA E DEONTOLOGIA NO EXERCÍCIO DA SOCIOLOGIA Novos desafios
}

\section{ETHICS AND DEONTOLOGY IN THE EXERCISE OF SOCIOLOGY New challenges}

\author{
Maria Manuel Vieira \\ Instituto de Ciências Sociais, Universidade de Lisboa. Av. Prof. Aníbal Bettencourt, 9, 1600-189 Lisboa, Portugal. \\ Email: mmfonseca@ics.ulisboa.pt
}

\author{
Ana Matias Diogo \\ CICS.NOVA.UAc/CICS.UAc, Faculdade de Ciências Sociais e Humanas, Universidade dos Açores. \\ R. da Mãe de Deus, 9502 Ponta Delgada, Portugal. Email: ana.is.diogo@uac.pt
}

\author{
Ana Paula Marques \\ Departamento de Sociologia, Instituto de Ciências Sociais, Universidade do Minho \& Centro de Estudos de \\ Comunicação e Sociedade (CECS). Campus de Gualtar, 4710-057 Braga, Portugal. Email: amarques@ics.uminho.pt
}

\begin{abstract}
Resumo: Este artigo constitui uma abordagem exploratória ao tema da ética e da deontologia em Sociologia. A partir do repto feito pela Direcção da Associação Portuguesa de Sociologia ao seu Conselho Deontológico para proceder à revisão do código que regulamenta a actividade científico-profissional dos sociólogos em Portugal, este ensaio tem por objectivo identificar alguns dos desafios que hoje se colocam ao exercício desta actividade e que urge ver equacionados nessa actualização normativa. O suporte empírico desta reflexão baseia-se na recolha e análise documental de regulamentos deontológicos em Ciências Sociais afins, bem como das cartas de princípios éticos elaboradas pelas principais associações europeia e internacional de sociólogos. Este confronto comparativo permite delimitar um conjunto de nove temas dilemáticos e uma sugestão final, que pretendem ser contributos para desencadear um debate alargado à comunidade de sociólogos sobre ética e deontologia profissional.
\end{abstract}

Palavras-chave: deontologia, ética, associação profissional, Sociologia.

\begin{abstract}
This article is an exploratory approach to ethics and deontology in Sociology. It aims to identify some of the challenges that are currently posed to the exercise of this activity, based on the challenge of the Portuguese Sociological Association to its Deontological Council to review the code that regulates the scientific and professional activity of sociologists in Portugal. The empirical support for this reflection is based on the collection and documental analysis of deontological regulations in related social sciences, as well the ethical principles elaborated by the main European and international associations of sociologists. This comparative exercise allowed for the development of nine dilemmatic themes and a final suggestion. These are expected to contribute to trigger a broad debate on professional ethics among the community of sociologists.
\end{abstract}

Keywords: deontology, ethics, professional association, Sociology. 


\section{Introdução}

Em finais de 2016, o Conselho de Deontologia (CD) da Associação Portuguesa de Sociologia (APS) deu início a um trabalho de reflexão sobre questões éticas e deontológicas colocadas à Sociologia na actualidade, que servisse de base para um debate alargado à comunidade de sociólogos sobre as alterações a introduzir no actual Código Deontológico da Associação por forma a adequá-lo aos novos desafios que hoje se colocam ao exercício desta atividade profissional. Para tanto, no âmbito daquele Conselho foram constituídos três grupos de trabalho: um primeiro, dedicado à ética e deontologia no ensino da sociologia; um segundo, que se debruçaria sobre a ética e deontologia na atividade profissional dos sociólogos; e um terceiro, mais centrado na ética e deontologia na atividade científica, composto pelas autoras deste artigo.

Com o propósito de contribuir para a atualização do Código Deontológico, nele identificando eventuais domínios de atuação em falta, em particular no que toca ao exercício da actividade científica, este grupo ensaiou uma breve análise exploratória de códigos referentes a outras áreas Ciências Sociais, bem como dos princípios éticos convencionados pela mais relevante associação europeia (European Sociological Association) e mundial (International Sociological Association) da Sociologia. Os resultados deste exercício foram apresentados e debatidos publicamente num encontro promovido pela APS em 2018, em Lisboa.

Para muitos, o Código Deontológico da APS revelaria hoje áreas a descoberto pelo facto de inexistirem ou serem incipientes à data da sua elaboração (1992). Que áreas são essas e que mudanças se terão operado que justifiquem a necessidade de uma revisão do Código Deontológico? Em particular, que novos desafios académico-científicos são hoje colocados aos sociólogos, que não se colocavam em 1992 ?

Este artigo, de âmbito exploratório, pretende dar contributos para a resposta a estas questões. Partindo de uma análise preliminar a vários códigos deontológicos, nacionais e internacionais, realizada por um dos grupos de trabalho criados pelo Conselho de Deontologia durante o mandato 2016-2018,1 o ensaio ora apresentado elenca algumas das pistas então reveladas (Vieira, Diogo \& Marques, 2018) e expande a sua abrangência, incluindo agora uma reflexão dedicada aos desafios do fazer Sociologia.

O roteiro deste artigo inicia-se com uma clarificação dos conceitos centrais mobilizados nesta reflexão - ética e deontologia - por forma a evitar ambiguidades semânticas no uso dos mesmos. Depois de uma breve referência às opções metodológicas que sustentaram a pesquisa exploratória realizada, baseada na análise documental de regulamentos deontológicos, segue-se a apresentação de algumas 
das pistas identificadas, posteriormente retomadas e outras acrescentadas para o caso específico da Sociologia, articulando, sempre que possível, as novas configurações que elas comportam com o contexto societal em que emergem.

\section{De que falamos quando falamos de ética?}

Como se sabe, a comunicação é constitutiva do processo de conhecimento (Pombo, 2000). Em termos gerais, a comunicação entre pares está na base da legitimação da ciência; por sua vez, a comunicação entre gerações, nomeadamente através do ensino, garante a transmissão aos mais novos do conhecimento científico acumulado pelos que lhes antecederam; e é ainda a comunicação entre ciência e sociedade, sobretudo através da divulgação científica, que permite a difusão alargada do conhecimento (Pombo, 2000).

No caso das Ciências Sociais, a comunicação adquire um estatuto adicional: ela representa a matéria-prima para a produção de conhecimento científico sobre o social. Dada a especificidade de que estas ciências se revestem - a familiaridade com o mundo social partilhada por observadores e observados, bem como a capacidade reflexiva possuída por todos os intervenientes - a linguagem, enquanto instrumento predominante de comunicação em Ciências Sociais, deve merecer cuidados redobrados. Para limitar a ambiguidade gerada pelo carácter polissémico da linguagem comum, a linguagem formal destas ciências deverá proceder à "fixação controlada da significação" (Almeida \& Pinto, 1990, p. 31) através da construção e definição de conceitos.

Importa assim, desde logo, iniciar esta reflexão delimitando os conceitos de "ética" e "deontologia". Por "ética", entender-se-á doravante o "conjunto de princípios morais, pelos quais o indivíduo deve orientar o seu procedimento." (Morais, 1992, p. 515). Por sua vez, "deontologia" significa literalmente a "ciência dos deveres" (Morais, 1992, p. 229). Abordar a "ética e deontologia" na actividade científica dos sociólogos remete, então, quer para a observância dos valores morais que inspiram as condutas individuais de quem é profissional da sociologia; quer para a codificação e/ou regulação dos deveres de desempenho a observar na actividade profissional dos sociólogos. ${ }^{2}$ Fenómenos como a fraude académica ${ }^{3}$ ou científica ${ }^{4}$ podem ser classificados como condutas do foro ético, deliberadamente cometidas pelos sujeitos que as protagonizam, ao passo que os regulamentos e códigos que enquadram o exercício da profissão referem-se à deontologia e, por isso, à jurisprudência aplicada aos actos profissionais.

Como se depreende, ética e deontologia não deixam de estar imbrincadas. Se a primeira se refere a um amplo espectro de práticas que, num dado tempo e contexto 
societário, são colectivamente percepcionadas como adequadas ou, pelo contrário, inaceitáveis do ponto de vista moral, a segunda tem por base um conjunto mais reduzido de condutas, avaliadas como aceitáveis e até mesmo desejáveis, que serão objecto de estabilização e organização num corpo de normas que se convenciona dever reger a (boa) prática profissional. Logicamente, este procedimento exclui do seu escopo, condenando-as, condutas avaliadas como eticamente reprováveis.

Para responder às questões que inspiraram este estudo, não se poderá deixar de considerar a ética e a deontologia, duas dimensões intrinsecamente associadas à produção de conhecimento científico sobre o social.

\section{Da exploração inicial de dados...}

Com o objetivo de avaliar quais as temáticas a descoberto no Código da APS, o grupo de trabalho referido, dedicado à ética e deontologia na actividade científica, procedeu a uma abordagem em duas etapas: uma primeira, envolvendo a recolha e análise de vários códigos deontológicos disponibilizados nos websites de várias instituições/associações profissionais afins na área das Ciências Sociais; ; seguidamente, identificou algumas pistas preliminares para se pensar novos desafios colocados a quem pretende fazer Sociologia.

Assim, sem preocupações de exaustividade ou de representatividade, numa lógica marcadamente exploratória, foram pesquisados ao todo 11 websites com vista à recolha de códigos e/ ou regulamentos de natureza deontológica. A diversidade de áreas disciplinares nas Ciências Sociais, por um lado, e as diferentes escalas geográficas de abrangência das convenções deontológicas no domínio da Sociologia, por outro, constituíram os critérios que orientaram a pesquisa.

No que se refere ao universo sociológico, para além do Código Deontológico da APS (1992), de âmbito nacional, foram ainda objeto de análise o documento Ethical Guidelines, da European Sociological Association (2015) e o Code of Ethics, da International Sociological Association (2001), de abrangência europeia e internacional, respectivamente.

Já no que concerne as restantes Ciências Sociais, e sem pretensão de exaustividade, mas de alguma abrangência disciplinar, foram pesquisados os websites das seguintes entidades: Associação Portuguesa de Geógrafos, Associação Portuguesa de Antropologia, Associação Portuguesa de Ciência Política, Associação Portuguesa de História Económica e Social, Associação dos Profissionais do Serviço Social, Ordem dos Psicólogos, Ordem dos Economistas eSociedade Portuguesa de Ciências da Educação, por forma a recolher os documentos reguladores do exercício da atividade dos seus profissionais. 
Após a recolha empírica estar concluída (Dezembro de 2017), iniciou-se então a leitura extensiva dos documentos e a análise de conteúdo muito preliminar dos mesmos, focada apenas na clarificação do que os distingue, mas também do que os une de forma substantiva.

Esta análise permitiu ao grupo de trabalho avançar, num segundo momento, para uma apresentação sucinta de alguns dos desafios que se colocam hoje aos produtores de Ciências Sociais, em evento organizado pela APS (Vieira, Diogo e Marques, 2018).

Partindo dessa matéria prima, procede-se agora à densificação de algumas dessas pistas e à identificação de outras entretanto equacionadas. É dos resultados dessa pesquisa e reflexão que se dará conta de seguida.

\section{...às reflexões que os resultados suscitam}

\section{Ciências Sociais e regulação deontológica: Notas preliminares}

Um primeiro sobrevoo aos websites seleccionados permite concluir que existe uma relativa diversidade na regulação deontológica da actividade profissional de cada Ciência Social. Com efeito, de entre o conjunto analisado distinguem-se três modalidades possíveis de regulação, muito ancoradas, por sua vez, ao formato jurídico-profissional escolhido por cada comunidade científica. Uma delas traduz-se na ausência de carta deontológica própria por parte de associações profissionais (Associação Portuguesa de Geógrafos, Associação Portuguesa de Ciência Política, Associação Portuguesa de História Económica e Social, Associação dos Profissionais do Serviço Social ${ }^{6}$ e Associação Portuguesa de Antropologia), o que as remete explicita (caso da Antropologia) ou implicitamente para a observância das regras dos códigos internacionais existentes na respectiva área. Outra forma de regulação adoptada por algumas associações profissionais consiste na existência de um código deontológico próprio, elaborado internamente por associados, e de um órgão de arbitragem para questões éticas (Conselho de Deontologia), representado nesta amostra exploratória pela Associação Portuguesa de Sociologia e pela Sociedade Portuguesa de Ciências da Educação. Uma modalidade alternativa de controlo deontológico consiste na figura da Ordem Profissional (casos da Psicologia e da Economia), o que envolve um escrutínio bastante mais rígido decorrente de um ordenamento jurídico-legal aplicável a este modelo associativo.

Uma segunda observação a retirar da pesquisa nos websites remete para a temporalidade distinta na criação dos códigos e regulamentos analisados. Neste particular, os sociólogos elaboram e aprovam o seu Código Deontológico no início dos 
anos noventa (1992), a Ordem dos Economistas apresenta, à data da sua criação (1998), um capítulo sobre deontologia profissional no decreto-lei que a institui; a Ordem dos Psicólogos dispõe de um Código Deontológico desde 2011, e a Sociedade Portuguesa de Ciências da Educação publica o seu em 2014. À escala internacional, os regulamentos deontológicos produzidos pelas duas principais associações que agrupam sociólogos de vários países surgem já nos anos 2000: o Code of Ethics da International Sociological Association (ISA) data de 2001, e a Ethical Guidelines, da European Sociological Association (ESA), é publicado recentemente, em 2015.

Uma terceira característica diferenciadora identificada na abordagem preliminar aos códigos, desta vez aqueles que regem especificamente o exercício da sociologia refere-se ao contraste entre dimensões universalistas e dimensões localistas na matriz de deveres contida em cada um. Assim, verifica-se que os Ethical Guidelines da European Sociological Association se distinguem dos restantes códigos (APS e ISA), ao compor uma lógica universalista com referências de âmbito regional, sublinhando a matriz cultural europeia e os seus valores como horizonte regulador de práticas a seguir pelos sociólogos associados (ex: "Reconhecer os contributos europeus para a concepção e desenvolvimento de uma cultura democrática, de direitos humanos e de ideais de justiça global").

Não obstante, o que emerge em comum nos seis códigos deontológicos efectivamente existentes e consultados aquando da pesquisa (a saber, os da Associação Portuguesa de Sociologia, da Sociedade Portuguesa de Ciências da Educação, da Ordem dos Economistas e da Ordem dos Psicólogos, para além dos da European Sociological Association e da International Sociological Association) é mais relevante do que aquilo que os diferencia. Da leitura dos textos destacam-se quatro preocupações basilares que importa referir, uma vez que elas condensam velhas e novas questões, com particular impacto na investigação científica, inspirando a subsequente reflexão (ponto 4.2.) centrada doravante no exercício da Sociologia e consequentes desafios regulatórios - que constitui o cerne deste ensaio.

Os cuidados éticos com a intervenção em contextos profissionais são uma dessas preocupações comum, alertando-se nos vários textos para as cautelas a ter relativamente a potenciais conflitos de interesse de ordem profissional, bem como para as preocupações adicionais a ter com os outros interlocutores (clientes, colegas e outros profissionais).

Outro dos tópicos identificados, com especiais repercussões em matéria de independência profissional, refere-se aos cuidados a ter com a protecção e direitos de propriedade, publicação e difusão da informação.

Uma terceira preocupação basilar envolve a qualidade da informação difundida pelos profissionais. Em particular, manifestam-se nos textos recolhidos preocupações 
com a conduta ética na prestação de declarações públicas, no sentido de os profissionais (das respectivas Ciências Sociais) lhes responderem adequadamente, preservando o bom nome da ciência que representam.

Por último, uma questão premente, inscrita nos códigos mais recentes, refere-se ao desafio colocado pelas novas acessibilidades a informação e preservação de dados que as novas TIC vêm oferecer. Este é um domínio que nos últimos anos tem suscitado um forte debate público, com consequências ético-filosóficas e jurídicas que importa acolher numa reflexão sobre o fazer Sociologia na actualidade.

É o que se fará seguidamente, explorando-se estes e outros temas relevantes, do ponto de vista do exercício da actividade científica da Sociologia, com o propósito de contribuir para a revisão do Código Deontológico que regula esta profissão.

Sociologia e novos desafios na actividade científica: Questões para o debate ético e deontológico

1. A primeira das preocupações já elencadas, contida nos códigos consultados - os cuidados éticos a ter na intervenção em contextos profissionais - tem respaldo no Código Deontológico da Sociologia. Quer no ponto referente à "Prática da Sociologia", quer no ponto especificamente dedicado às "Relações Profissionais", alerta-se os sociólogos para as cautelas a ter relativamente a potenciais conflitos de interesse de ordem profissional, bem como para as preocupações adicionais a ter com os interlocutores (clientes, colegas e demais profissionais).

Ora, novos desafios parecem emergir neste domínio, associados ao processo em curso, de intensificação da internacionalização da pesquisa. A proliferação de regras, regulamentos e procedimentos ético-deontológicos e sua adopção mimética e generalizada à escala global não deixa de colocar a questão do eventual risco de padronização que tal pode implicar. Por outras palavras, será que a internacionalização acrescida dos processos (equipas, modelos de gestão científica, métodos e técnicas aplicados...) e produtos de pesquisa (língua de divulgação, formato de redacção e apresentação de resultados, tendo em conta modelos de escrita científica impostos por revistas e publicações cotadas em rankings académicos) poderá traduzir-se no risco de uniformização de procedimentos, contrários ao exercício de reflexividade teórico-metodológica a observar em cada novo processo de produção de conhecimento? Até que ponto tais procedimentos não contribuem para reiterar invisibilidades socio-culturais por referência à orientação europeísta ou anglo-saxónica adoptada como padrão? Até que ponto a aceitação acrítica de tais procedimentos não poderá desqualificar modos locais de trabalhar mais adequados às práticas culturais aí prevalecentes (maior/menor formalidade no acesso aos sujeitos, maior/menor prevalência de convenções de tipo contratual escritas, por contraste com acordos firmados na oralidade com os sujeitos, 
etc.)? Um formato-padrão de consentimento informado, exaustivamente explanado em vários documentos de apoio aos cientistas sociais elaborados pela Comissão Europeia (EC, 2018a e 2018b), não constituirá justamente um exemplo de "normalização" (europeizante, neste caso) de procedimentos de pesquisa? Em caso afirmativo, o risco de padronização processual do "artesanato científico" (Booth, Colomb \& Williams, 2003) não é contrário à própria especificidade das Ciências Sociais, bem recordada no preâmbulo do Código Deontológico da APS:

A formulação dos princípios deontológicos dos sociólogos não ignora aquisições cognitivas fundamentais da sociologia, nomeadamente quanto ao carácter relacional, socialmente construído e mutável da realidade social, quanto às assimetrias de recursos e poderes existentes na sociedade e quanto à diversidade e relatividade das culturas (APS, 1992, p. 2)?

Por outro lado, a crescente colaboração internacional coloca em cena múltiplos financiadores públicos e privados que tendem a apresentar diversos níveis de constrangimento. Perante a multiplicação de bolsas e concursos para financiamento de projectos à escala global, a existência de distintas entidades financiadoras e a constituição de equipas científicas de âmbito internacional (não necessariamente compostas apenas por cientistas sociais), a regulação da actividade de produção científica desloca-se para um patamar multi-escalar. Na verdade, assiste-se a um fenómeno de sobreposição de princípios orientadores da conduta a observar na investigação científica definidos a nível nacional, europeu ou mesmo internacional, o que pode provocar alguma entropia na regulação do exercício ético da pesquisa. Veja-se o caso dos sociólogos: para além dos códigos das instituições em que estão filiados, do Código Deontológico da APS, dos Ethical Guidelines da ESA e do Code of Ethics, da ISA, aqueles que estiverem a desenvolver projectos de investigação financiados por fundos europeus deverão seguir preceitos éticos inscritos na Carta dos Direitos Fundamentais da União Europeia, na Convenção Europeia dos Direitos do Homem e protocolos complementares, bem como no Código Europeu de Conduta para a Integridade Científica adotado pela ALLEA - All European Academies. Perante esta multiplicidade de cartas, códigos e convenções jurídicas, a questão que se coloca é: que ordenamentos seguir? E a que instância(s) recorrer para dirimir eventuais conflitos?

2. A segunda das preocupações a que os códigos analisados são sensíveis prende-se com a protecção e direitos de propriedade, publicação e difusão da informação. Relativamente a este tópico, alguns dos textos analisados chamam a atenção para a questão sensível de garantia e preservação de direitos de propriedade 
intelectual na relação com actividades de supervisão e integração em equipas colectivas de investigação. A autoridade científica de um orientador ou coordenador de estudo não pode atropelar ou sequer obliterar autorias legítimas do orientado ou de membro(s) da equipa, a menos que tenha efectivamente contribuído com trabalho próprio para o produto/publicação final em causa. Por sua vez, importa clarificar os limites à utilização individual da pesquisa realizada em equipa, seja para fins académicos, seja para outros fins, como os de prestação ou venda de serviços. A difusão da informação obtida em contexto académico junto de públicos mais alargados deve igualmente preservar a sua qualidade original, sem sofrer danos ou deturpações.

Neste particular, também o Código Deontológico elaborado pela APS contém um conjunto de indicações normativas referentes à "Autoria e Publicações" (direitos autorais, explicitação de autorias, referenciação bibliográfica, pluralidade de orientações teóricas e metodológicas) a que se soma ainda uma importante menção a direitos de propriedade intelectual de orientandos, no domínio do "Ensino e Orientação": "Nos trabalhos que apresentem, os sociólogos que exerçam actividades de ensino e orientação têm a obrigação de reconhecer explicitamente as eventuais contribuições de alunos e orientandos, e não devem apresentar como seus trabalhos por eles realizados." (APS, 1992, p. 6).

Porém, a alteração dos padrões de produção de conhecimento científico nas últimas décadas tem colocado um conjunto de novos desafios éticos. A aceleração comunicacional que as novas tecnologias de informação e comunicação vieram propiciar parece ter imposto - à ciência, mas não só - a intensificação dos ritmos como um fim em si mesmo, desqualificando tudo o que signifique abrandamento, lentidão, demora. Ora, como bem referem Stengers e Déléage (2014), esta injunção quase moral para a aceleração dos ritmos, associada à competitividade instalada à escala global, pode ter impactos nefastos na ciência. A compressão, ou mesmo a anulação do tempo para pensar, levantar questões pertinentes e refletir sobre elas impostos aos cientistas, a intensificação da pressão para publicar a todo o custo e, em particular, a bibliometria como instrumento nuclear de avaliação de produtividade científica (condensada na conhecida frase "publish or perish") poderá estar na base da proliferação de práticas de má conduta ética - desde situações de conflitos de interesse até fraudes científicas (fabricação, falsificação e plágio) (Strgar \& Vukadinovic, 2018) com impactos na fiabilidade do conhecimento científico. É particularmente frequente verificar-se más práticas em questões de autoria, nomeadamente a atribuição de coautorias fictícias, quer no contexto das relações entre pares, em que a falsa coautoria é um processo de reciprocidade que tem como principal objectivo potenciar o número de publicações anuais de cada (alegado) autor; quer também no contexto de 
relações hierárquicas de poder, como as de orientador-orientando ou entre colegas com estatutos desiguais, podendo aqui o processo ser coercivo. A estas deverá somar-se a previsível intensificação de práticas de auto-plágio, ou seja, da publicação do mesmo texto em várias plataformas editoriais, nacionais e internacionais, ampliando de forma exponencial a produtividade final com que o visado se apresenta publicamente.

O atual código deontológico da APS refere-se a alguns aspetos genéricos sobre a prática de publicar, mas não deveria insistir neste ponto, tendo em conta o que esta crescente pressão para publicar estará a fomentar?

3. Outro dos cuidados éticos identificados nos documentos analisados, sobretudo nos mais recentes - a conduta ética na prestação de declarações públicas com vista à preservação do bom nome da ciência que representam - prende-se com um fenómeno pouco presente no Código Deontológico da APS. Um dos desafios que se coloca hoje à Ciência (Social), mais do que no passado, é o que advém da mediatização da Ciência e, nessa medida, nos padrões de conduta ética dos seus divulgadores. Em sociedades crescentemente mediadas pelas tecnologias de informação e comunicação, e num contexto de concorrência académica acrescida, a reputação (de cada instituição de ensino superior, de cada profissional) adquire um valor central. Como Howard Becker (1982) indica em trabalho pioneiro sobre o tema, a reputação é um processo social; e, dimensão importante, a visibilidade constitui um dos seus ingredientes fundamentais. Nesse contexto, como a Sociologia vem propondo, o processo de construção reputacional envolve, entre outros aspectos, o fabrico comunicacional de um nome - o "renome" - referente à visibilidade pública de uma entidade tida como reputada (Borges, 2014).

Ora, quer nos media tradicionais, quer na web, instalou-se uma competição impiedosa pela conquista de visibilidade, reconhecimento e reputação. Tal conduz muitos profissionais da Sociologia à tentação de protagonismo no espaço público através da visibilidade mediática, por forma a aceder ao star system ou ao mundo dos like (Cardon, 2013) ...Essa mobilização intensiva faz com que alguns sociólogos se disponham a falar do que sabem e, também, do que não sabem, confundindo o plano da competência profissional - necessariamente limitada - com o plano da auto-celebração individual - por definição, ilimitada. A preocupação em garantir rigor, competência e responsabilidade nas declarações públicas feitas por sociólogos, para não descredibilizar a Ciência em nome da qual falam, encontra-se implicitamente sugerida num único artigo do Código Deontológico da APS - mas nem sempre é respeitada: 
Os sociólogos devem exercer a sua profissão de acordo com os mais elevados padrões de competência profissional ao seu alcance. Da sua conduta profissional devem fazer parte a exploração de todas as potencialidades da sociologia e uma permanente actualização de conhecimentos. Os sociólogos devem igualmente ter presente os limites da sua disciplina e os seus próprios limites pessoais (APS, 1992, p. 3)

Importaria, pois, aquando da revisão deste Código, reforçar esta indicação de forma mais inequívoca.

4. Um desafio bastante recente sobressaiu também na pesquisa exploratória efetuada: ele tem a ver com as TIC, com as novas acessibilidades a informação e com a preservação de dados que aquelas exigem. Como se depreende, a utilização crescente das TIC (ex. pesquisa online e softwares de tratamento de dados) e, em especial, do Big Data no contexto de investigação e prática profissional, coloca problemas de preservação dos dados pessoais e de definição de limites ético-deontológicos à sua recolha e utilização. Simultaneamente, também a maior transparência exigida hoje na difusão de procedimentos de pesquisa e gestão de dados (ex: dados pessoais, partilha de informação, publicação de dados) levanta outros desafios. Nenhuma destas questões se encontra espelhada no Código Deontológico da APS, produzido num tempo em que a adopção e generalização destas ferramentas se encontrava praticamente ausente do trabalho científico.

Um domínio regulatório a incluir na revisão do Código Deontológico dos sociólogos refere-se, pois, às novas tecnologias de informação e comunicação (TIC) e gestão da informação. A chamada terceira revolução industrial, assente no desenvolvimento de tecnologias que permitem criar, manipular e transmitir informação (Oliveira, 2019), vem nos últimos anos alterar substancialmente o tempo e a forma como os indivíduos comunicam. Na verdade, as novas TIC abrem um amplo campo de acção para as Ciências Sociais, quer enquanto objecto de estudo, quer enquanto fonte de dados. Não obstante, o seu uso requer cuidados éticos acrescidos, uma vez que estas tecnologias geram questões sensíveis, nem sempre tidas em conta pelos produtores de conhecimento. Por um lado, as conexões tecnológicas podem permitir o acesso à identificação de IPs de origem dos sujeitos on-line, colocando em causa o princípio de preservação do anonimato garantido nas pesquisas e consagrado no Código Deontológico. Por outro lado, as novas tecnologias de informação e comunicação podem igualmente propiciar o risco - caso cuidados adicionais não sejam acautelados - de acesso aos dados de pesquisa enviados pela internet por parte de pessoas não autorizadas. Por sua vez, o uso das redes sociais como fonte pode colocar a questão da obtenção do consentimento informado de dados nelas originados, no caso de os utilizadores desconhecerem que estão a ser utilizados como sujeitos 
da pesquisa. Ademais, a por vezes ambígua fronteira entre público e privado no uso das redes sociais pode conduzir a equívocos éticos de complexa resolução, tendo em conta o imperativo do consentimento (Peixoto, 2016) requerido na organização da vida social contemporânea.

É importante também reconhecer que, se têm sido avançados benefícios na utilização de Big Data, nomeadamente na monitorização do comportamento humano e seu potencial preditivo, há igualmente riscos e possíveis desvantagens que importa não escamotear. Um deles prende-se com o cumprimento do requisito da transparência da informação: é crucial ser informado acerca do modo como foram produzidos os dados e compreender as decisões que são tomadas por força do recurso às máquinas inteligentes. Um outro tem a ver com o modelo da chamada "aprendizagem automática" (Oliveira, 2019, p. 60), baseado no princípio de que os computadores podem aprender com a experiência, quando aplicado à produção de conhecimento sociológico. Neste caso, quando a máquina passa a aprender de per si a prever comportamentos humanos a partir da informação que lhe é fornecida, sem a necessária apreensão dos níveis estruturais e interactivos da acção social, é de artificialismo do potencial preditivo do comportamento humano que na realidade se poderá tratar...

Para além destas referências, destacadas da leitura dos códigos consultados, importa reflectir sobre outras frentes dilemáticas que colocam novos (ou renovados) desafios à tarefa de produção de conhecimento científico sobre o social.

5. Uma delas refere-se às potenciais tensões entre protecção de direitos humanos e possibilidades de pesquisa. Justamente, o reforço da noção de direitos humanos à escala mundial traz, como corolário, a preocupação acrescida com a protecção dos seres humanos, em geral, e dos considerados especialmente vulneráveis (crianças, portadores de deficiência, minorias...), em particular, o que coloca não apenas maior exigência nos padrões de conduta ética por parte dos cientistas sociais, mas também novos reptos.

Por um lado, a percepção socialmente disseminada de direitos a proteger poderá reforçar blindagens de acesso a certas populações por parte de potenciais gatekeepers (pais, directores de instituições, ministério(s) de tutela, cuidadores, entre outras figuras-guardião possíveis).

Por outro lado, no caso de populações ou grupos não tutelados, mas socialmente vulneráveis, a conquista de um maior empowerment alcançado no contexto de lutas por reconhecimento (Fraser, 2007) - como consequência ou não dos efeitos de "desvendamento" que a ciência oferece, propícios à reflexividade acerca da sua condição - pode envolver protocolos complexos de negociação entre 
observador e observado(s) que, em última análise, impõem formas de pressão e/ ou de condições de acesso contrárias aos requisitos inerentes à produção de conhecimento científico. Importa reiterar que a relação "observador/ observado" e os processos de recolha de informação são eles próprios processos sociais sui generis de produção de conhecimento científico (Almeida \& Pinto, 1986) e, nessa medida, uma permanente reflexividade epistemológica não pode ser dispensada. No actual contexto social, mais conhecimento pode significar, paradoxalmente, mais vulnerabilidade científica perante a sua potencial captura e instrumentalização por parte de uma diversidade de interesses concorrentes (Eizagirre, 2017, p. 107). Apesar de a submissão a interesses alheios aos critérios científicos ser eticamente condenada pelo Código regulador da prática da Sociologia ("os sociólogos devem procurar conseguir a maior objectividade possível na análise da realidade social. Trata-se, não de considerar a produção de conhecimento sociológico como socialmente neutra, mas de evitar distorções deliberadas resultantes de interesses ou convicções (...)") (APS, 1992, p.3), a questão que se coloca tem a ver com possibilidades de pesquisa: será que a potencial radicalização cívico-política dos sujeitos ou dos seus zeladores não compromete o futuro do artesanato sociológico? Será que a prazo o sociólogo não se confrontará com a impossibilidade de estudar sociologicamente certos temas ("sensíveis") e certas populações ("vulneráveis")?

6. Um outro conjunto de questões gira igualmente em torno de dificuldades de acesso ao campo, mas por motivos distintos: trata-se, desta vez, da relação entre proliferação de pesquisas e angariação de sujeitos. Na contemporaneidade, e associado ao aumento das qualificações e à generalização de formas de gestão e controle baseadas na monitorização assídua de resultados, assiste-se a uma pericialização alargada nos vários domínios da vida social. Proliferam especialistas e, em particular, observa-se a interferência do exercício da expertise em Ciências Sociais no quotidiano dos indivíduos. Estes já não são apenas solicitados para responder a inquéritos conducentes à produção de estatística oficial (INE), mas passam a ser regularmente confrontados com sondagens e pesquisas de mercado, através de inquirição de rua ou telefónica, bem como com inquéritos de avaliação da qualidade de serviços prestados nos mais variados domínios da existência (hospitais, bancos, hotéis, telecomunicações, restaurantes, seguros, manutenção automóvel...) para já não falar do obrigatório preenchimento de instrumentos de inquirição constantes da avaliação do seu desempenho, em contexto profissional. Neste âmbito, um dos desafios que se coloca é o da disponibilidade dos sujeitos para participar em pesquisas académicas. O cansaço, ou mesmo a exaustão dos quotidianamente assediados cidadãos poderá tornar difícil a tarefa de angariar inquiridos, 
entrevistados, observados no contexto da investigação académica... Para o contrariar, parece estar a popularizar-se em Ciências Sociais práticas de aliciamento de participantes para a pesquisa através da oferta de pequenos bens ou de pagamento, à imagem do que sucede com as ciências biomédicas ou os testes médico-farmacêuticos. O trabalho de sociólogos em equipas interdisciplinares pautadas por padrões de conduta relativamente invulgares na Sociologia pode, justamente, estar a contribuir para a naturalização desses procedimentos de angariação premiada. No âmbito do debate conducente à revisão do Código Deontológico, importa também discutir os problemas éticos que tais práticas poderão colocar.

7. Se estas questões se colocam hoje genericamente à tarefa de "fazer Sociologia", o contexto específico em que ela tem lugar não deixa de emprestar contornos singulares à sua concretização. Assim, não se pode concluir este ensaio sem mencionar alguns desafios particulares associados ao contexto português actual.

O primeiro ancora-se ao chamado "new public management",, $7 \mathrm{em}$ popularidade crescente na gestão da administração pública, potenciada pela situação de crise económica vivida nos últimos anos no país. A tendência de crescimento anémico de dotações orçamentais públicas para investigação e desenvolvimento (I\&D), em \% do PIB (INE/Pordata, 2019), tem vindo a colocar pressão institucional sobre os investigadores para se transformarem em "empresários por contra de outrem", angariando a todo o custo financiamento para a pesquisa que possa simultaneamente verter mais-valias financeiras que permitam custear os "custos de operação" (overheads) da instituição empregadora. Até que ponto este imperativo, ao impelir os investigadores a aceitarem todo e qualquer tipo de solicitação, não pode estar a promover situações que comprometem a qualidade da produção de saber sociológico? Ao não serem oferecidas pelos financiadores as condições mínimas exigíveis para uma pesquisa séria e rigorosa, seja em termos de duração (ex: pode-se fazer uma pesquisa em 15 dias?), seja em termos da independência científica para produzir conhecimento cujos resultados podem contrariar a agenda político-ideológica ou os interesses particulares de quem o encomenda (ex: pode-se alterar conclusões de pesquisas para agradar a financiadores?), não será legítimo recusar encomendas de estudos - como aliás o sugere o Código Deontológico da APS - , por muito financeiramente aliciantes que estas possam ser? Neste caso, que garantias oferece o Código e o Conselho de Deontologia da APS na defesa dos seus pares, em caso de diferendo com a instituição empregadora a este propósito?

Esta questão é tanto ou mais pertinente em conjunturas, como a que actualmente se vive em Portugal, de precarização acentuada do trabalho científico. No caso do Ensino Superior, os recentes inquéritos ao potencial científico e tecnológico 
nacional revelam um aumento da proporção de "bolseiros" no conjunto das situações profissionais aí existentes: de 38\%, em 2014, ascendem a 41\%, em 2016, ultrapassando mesmo a proporção de docentes e investigadores de carreira (DGEEC, 2016 , 2017, 2018). Ora, sabe-se como essa condição laboral, assente em contratos de duração limitada, é precária e incerta, atingindo particularmente os mais jovens que, na realidade, são um dos pilares de sustentação do edifício I\&D em Portugal: os investigadores com idades compreendidas entre os 25 e os 34 anos representavam, em 2016, 31\% do contingente total. A dependência hierárquica e funcional destes jovens cientistas face aos docentes e investigadores de carreira - e, de uma forma mais lata, relativamente às instituições de acolhimento e seus dirigentes torna-se mais acentuada, por força da vulnerabilidade da sua condição de precariedade, o que pode condicionar a forma como actuam cientificamente, submetendo-se às pressões institucionais de angariação de financiamento (a todo o custo) e de produtividade (intensiva), optando por vias que podem comprometer as boas práticas de conduta ética...

8. Neste contexto, importa reforçar a visibilidade e centralidade do código deontológico no exercício da Sociologia, enquanto horizonte regulador da conduta ética dos seus profissionais. Apesar de a sociologia portuguesa ter sido relativamente expedita na elaboração de um código de deveres profissionais, paradoxalmente muitos sociólogos parecem desconhecer o seu conteúdo ou, pelo menos, não o utilizar como recurso diário no seu desempenho profissional - nomeadamente, como instrumento legitimador de decisões éticas quanto a linhas vermelhas a não ultrapassar. Na verdade, será que o código deontológico da APS é referido e apresentado aos aprendizes de Sociologia na sua formação académica nas universidades portuguesas? Qual o espaço dedicado a abordar questões de ética profissional com os alunos dos cursos de Sociologia? Até que ponto o código deontológico é instrumento presente, i.e., efetivamente usado e invocado, na prática dos sociólogos e dado a conhecer a terceiros como regulador da sua prática? Embora nele se indique que "no estabelecimento de relações contratuais para o exercício das suas atividades profissionais, os sociólogos devem explicitar junto de empregadores, clientes ou financiadores a sua adesão a este código deontológico" (APS, 1992, p.5), será esta prática habitual?

9. Um último ponto merece destaque nesta reflexão. O código de conduta ética que inspira a comunidade sociológica internacional começa por referir que "a eficácia de um Código de Ética repousa principalmente na auto-disciplina e no auto-controle de quem a ele se aplica" (ISA, 2001). Semelhante apelo a um procedimento injuntivo 
auto-regulador decorre da recusa, relativamente consensual entre a comunidade sociológica portuguesa, em converter-se numa corporação seletiva, fechada e autorregulada, como o é a figura da Ordem Profissional. Esta recusa de fechamento advém, justamente, de argumentos fundamentados no seu próprio património científico, inspirados quer na sociologia das profissões, quer na sociologia das desigualdades sociais (Costa, 2018).

Ora, o princípio de autorregulação, baseado no mero voluntarismo individual na adopção de conduta ética adequada, é sem dúvida louvável, mas nem sempre seguido. Assim sendo, importa não escamotear a questão da forma como se poderão dirimir conflitos decorrentes de uma actuação profissional incorrecta ou mesmo fraudulenta. De uma forma genérica, a tendencial universalização do ensino superior e a relevância dos diplomas como meio de acesso ao mercado de trabalho e, mais especificamente, a escassez actual de lugares de carreira no ensino superior ou na administração pública - para onde uma proporção significativa de sociólogos outrora se dirigia - aumentando a competição pelos lugares disponíveis, são elementos que potenciam estratégias instrumentais que, para alguns dos seus protagonistas, dispensam uma ancoragem ética. Na previsão expectável de uma crescente actividade crítica e denunciadora de atropelos moralmente condenáveis (plágios, autoplágios, fraudes científicas e académicas) e de injustiças cometidas pelos pares ${ }^{8}$ (em concursos para entrada ou progressão na carreira, em candidaturas a projectos e financiamento, na contabilização de elementos de produtividade científica, etc.), as expectativas depositadas na APS e no seu Conselho de Deontologia enquanto órgão desejavelmente imparcial na arbitragem de conflitos são compreensivelmente elevadas. No entanto, por emanar de uma associação profissional, o seu alcance é forçosamente limitado. Tal como definidas no Código Deontológico, as incumbências deste Conselho têm um carácter genérico e tendencialmente preventivo, resumindo-se à "sensibilização, o esclarecimento, o aconselhamento, a arbitragem, a acumulação de exemplos e o aprofundamento das interpretações perante problemas deontológicos que lhe sejam colocados" (APS, 1992, p. 14). Em particular, a noção de "arbitragem" pode evocar uma amplitude jurisdicional bastante mais vasta e consequente do que aquela que na realidade este órgão dispõe. Coloca-se assim, perante a comunidade de sociólogos, a questão de identificar claramente o papel a esperar do Conselho de Deontologia desta Associação na arbitragem da conflitualidade interna. Que tipo de protecção e defesa de direitos dos profissionais da Sociologia face a más condutas e/ ou ameaças externas pode uma Associação como esta desencadear?

A resposta remete para a elaboração de pronúncias sem poder sancionatório que não o meramente simbólico. Caberá às instâncias institucionais de filiação de 
queixosos e prevaricadores avaliar e decidir acerca da gravidade do acto cometido e das acções a empreender. A este respeito, no entanto, as respostas têm sido geralmente frouxas e parecem estar muitas vezes aquém do esperado, como parece concluir-se de um recente estudo sobre o tema: prevalecem "concepções (do que é um comportamento fraudulento) altamente permeáveis à subjectividade de quem as avalia", à qual se somam, frequentemente, decisões baseadas em critérios de conveniência conjuntural das lideranças institucionais (Peixoto, Esteves, Seixas, Almeida \& Gama, 2016, pp. 208-209).

Para concluir, um apelo deixado aos leitores. A aleatoriedade conjuntural, subjectiva ou instrumental destas decisões não poderá justamente dar sentido à necessidade de criação de uma instância independente e escrutinável (uma Provedoria do Ensino Superior e Ciência?) que, à escala nacional, permita analisar e dirimir, com base em competência jurídica, mas também científica, conflitos e situações de manifesta injustiça académica e científico-profissional?

\section{Agradecimentos}

As autoras agradecem as úteis sugestões deixadas pelos revisores deste texto, que em muito contribuíram para a sua versão final. No entanto, a responsabilidade do conteúdo expresso e das eventuais imprecisões que este possa apresentar é da exclusiva responsabilidade das autoras.

\section{Contribuição dos autores}

As três autoras realizaram o trabalho empírico de pesquisa, recolha e análise dos documentos regulatórios indicados no texto. Maria Manuel Vieira elaborou inicialmente este texto e desenvolveu as propostas avançadas no ponto "Sociologia e novos desafios na actividade científica" que teve a revisão crítica das outras duas autoras. Todas as autoras aprovaram a versão final do texto.

\section{Notas}

Por decisão pessoal, as autoras do texto não escrevem segundo o novo acordo ortográfico.

1 O produto desse trabalho foi apresentado no encontro Ética e Deontologia dos Sociólogos - Desafios no ensino, na profissionalização e na actividade científica, ocorrido em 29 de Janeiro de 2018 no Instituto de Ciências Sociais da Universidade de Lisboa. 
2 O conceito de "actividade profissional" aplica-se aqui a todos os sociólogos que exerçam uma profissão em que a Sociologia constitua a matriz disciplinar de referência para a sua prática. A actividade académica e científica, a que este artigo se dedica de forma particular, representa tão-somente uma das múltiplas vertentes profissionais dos sociólogos.

3 Fraude Académica pode ser definida como "todo o acto ou omissão consciente que possa comprometer a justiça na avaliação dos desempenhos, competências e conhecimentos (...)" (Almeida, Seixas, Gama e Peixoto, 2015, p. 22)

4 Segundo Strgar e Vukadinovic (2018), apesar de existirem múltiplas propostas de definição para "fraude científica", os autores convergem no reconhecimento dos seus “(...) basic types, most frequently singling out plagiarism, fabrication and the falsification of data." (p. 119, sublinhado nosso).

5 Para efeitos deste estudo, assumidamente exploratório e ensaístico, optou-se por não incluir na análise códigos deontológicos de áreas científicas externas às Ciências Sociais.

6 Posteriormente à elaboração desta pesquisa, em Outubro de 2018, a Associação dos Profissionais do Serviço Social aprovou o seu código deontológico.

7 Este novo conceito de gestão pública assenta na aplicação de “(...) ideias próprias do mercado e do sector privado, baseando-se num racional liberal e na convicção da superioridade dos mecanismos de mercado, competição e interesses individuais como motivação para o trabalho (Martins, 2012, p. 15).

8 A "Petição pelo aumento das garantias de imparcialidade nos concursos da carreira docente universitária", citada no texto de Tavares, Lança e Sin (2015) é, simbolicamente, um exemplo dessa actividade de denúncia pública de situações vividas como injustas.

\section{Referências}

Almeida, F., Seixas, A., Gama, P., \& Peixoto, P. (2015). A fraude académica no Ensino Superior em Portugal: Um estudo sobre a ética dos alunos portugueses. Coimbra: Imprensa da Universidade de Coimbra.

Almeida, J. F., \& Pinto, J. M. (1986). Da teoria à investigação empírica. Problemas metodológicos gerais. Em A. Silva, \& J. M. Pinto (orgs.), Metodologia das ciências sociais (pp. 55-78). Porto: Edições Afrontamento.

Almeida, J. F., \& Pinto, J. M. (1990). A investigação nas ciências sociais (4ª ed.). Lisboa: Editorial Presença.

Associação Portuguesa de Sociologia (APS). (1992). Código deontológico. Lisboa: APS. Becker, H. (1982). Art worlds. Berkeley: University of California Press.

Booth, W. C., Colomb, G. G., \& Williams, J. M. (2003). The craft of research (2a ed.). Chicago \& Londres: The University of Chicago Press.

Borges, V. (2014). Reputação, mercado e território. O caso dos arquitetos. Sociologia, Problemas e Práticas, 74, 73-92. doi: 10.7458/SPP2014743201 
Cardon, D. (2013). Du lien au like sur Internet. Deux mesures de la réputation. Communications, 2(93), 173-186.

Costa, A. F. (2018). Sociólogos: Associativismo inclusivo versus fechamento corporativo. Sociologia ON LINE, (18), 81-87. doi: 10.30553/sociologiaonline.2018.18.4

Direção Geral de Estatísticas de Educação e Ciência (DGEEC). (2016). Inquérito ao potencial científico e tecnológico nacional 2014. Principais resultados por setor de execução. Lisboa: DGEEC - Ministério da Educação. Disponível em http://www.dgeec.mec.pt/np4/206/\%7B\$clientServletPath\%7D/?newsId=11\&fil eName=IPCTN14_Destaque_Setoriais_corrigido.pdf

Direção Geral de Estatísticas de Educação e Ciência (DGEEC). (2017). Inquérito ao potencial científico e tecnológico nacional 2015. Principais indicadores de iEd setoriais. Lisboa: DGEEC - Ministério da Educação. Disponível em http://www.dgeec.mec.pt/np4/206/\%7B\$clientServletPath\%7D/?newsId=11\&fil eName=IPCTN15_Resultados_Setoriais.pdf

Direção Geral de Estatísticas de Educação e Ciência (DGEEC). (2018). Inquérito ao potencial científico e tecnológico nacional 2016. Principais indicadores de iEd setoriais. Lisboa: DGEEC- Ministério da Educação. Disponível em http://www.dgeec.mec.pt/np4/206/\%7B\$clientServletPath\%7D/?newsId=898\&fi leName=IPCTN16_Destaques_Resultados_Setoriais.pdf

Eizagirre, A. (2017). Investigación e innovación responsables. Retos teóricos y políticos. Sociologia, Problemas e Práticas, 83, 99-116. doi:10.7458/SPP2017834400

European Commission (EC). (2018a). Ethics in social science and humanities. Disponível em http:/ / ec.europa.eu/research/participants/data/ref/h2020/other/hi/h2020_ethics-s oc-science-humanities_en.pdf

European Commission (EC). (2018b) Ethics and data protection. Disponível em http:/ / ec.europa.eu/research/participants/data/ref/h2020/grants_manual/hi/e thics/h2020_hi_ethics-data-protection_en.pdf

European Sociological Association. (2015). Ethical guidelines. ESA - European Sociological Association. Disponível em https:/ / www.europeansociology.org/ about-esa/governance/ethical-guidelines

Fraser, N. (2007). Reconhecimento sem ética?. Lua Nova, 70, 101-138.

Instituto Nacional de Estatística/Pordata (2019). Dotações orçamentais públicas para investigação e desenvolvimento (IED) em \% do PIB. Disponível em https://www.pordata.pt/Portugal/Dota\%c3\%a7\%c3\%b5es+or\%c3\%a7amentais+ p\%c3\% bablicas+para+investiga \%c3\%a7\%c3\%a3o+e+desenvolvimento+(I+D)+em+ percentagem + do+PIB-1099

International Sociological Association. (2001). Code of ethics. ISA - International Sociological Association. Disponível em https:/ / www.isa-sociology.org/en/ about-isa/code-of-ethics

Martins, P. G. B. (2012). As universidades fundacionais e o new public management (Dissertação de mestrado). ISCTE-IUL, Lisboa. 
Morais, A. (1992). Novo dicionário compacto da língua portuguesa (vol. II). Lisboa: Editorial Confluência.

Oliveira, A. (2019). Inteligência artificial. Lisboa: Fundação Francisco Manuel dos Santos.

Ordem dos Economistas. (1998). Decreto-Lei n. ${ }^{0} 174 / 98$ de 27 de Junho. Criação da Ordem dos Economistas. CAP. X Deontologia profissional. Em Diário da República n. ${ }^{\circ}$ 146/1998, Série I-A de 1998-06-27.

Ordem dos Psicólogos Portugueses. (2011). Código deontológico. Publicação / 21 abril 2011.

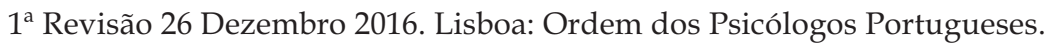
Disponível em https://www.ordemdospsicologos.pt/ficheiros/documentos/ web_cod_deontologico_pt_revisao_2016.pdf

Peixoto, P. (2016). Ética e questões deontológicas na sociologia e na sociedade do consentimento. Disponível em http://www4.fe.uc.pt/fontes/etica_deontologia_sociologia.html

Peixoto, P., Esteves, D., Seixas, A., Almeida, F., \& Gama, P. (2016). Políticas institucionais, em Portugal, relativas à fraude académica. Em F. Almeida, A. Seixas, P. Gama, P. Peixoto, \& D. Esteves (coord.), Fraude e plágio na universidade. A urgências de uma cultura de integridade no ensino superior (pp. 195-239). Coimbra: Imprensa da Universidade de Coimbra.

Pombo, O. (2000). Comunicação e construção do conhecimento. Revista de Educação, IX(1), 5-25.

Sociedade Portuguesa de Ciências da Educação. (2014). Carta ética. Disponível em http://www.spce.org.pt/PDF/CARTAETICA.pdf

Strgar, S., \& Vukadinovic, M. (2018). Legal aspects of scientific misconduct: Causes and possible solutions. Ethical Perspectives, 25(1), 117-141.

Stengers, I., \& Deléage, E. (2014). Ralentir les sciences, c'est réveiller le chercheur somnambule. Écologie \& Politique, (48), 61-74.

Tavares, O., Lança, V., \& Sin, C. (2015). Endogamia nas universidades portuguesas: Alguns casos. Em Estado da educação 2015 (pp. 270-278). Lisboa: Conselho Nacional de Educação.

Vieira, M. M., Diogo, A., \& Marques, A. P. (2018, Janeiro). Ética e deontologia na actividade científica. Comunicação apresentada no Encontro Ética e Deontologia dos Sociólogos. Desafios no ensino, na profissionalização e na actividade científica, Lisboa, Instituto de Ciências Sociais da Universidade de Lisboa.

Data de submissão: 28/08/2019 | Data de aceitação: 13/03/2020 